\title{
Tunable Inductors Using Integrated Vanadium Dioxide Phase Change Thin Films
}

\author{
Liangyu Li, ${ }^{1}$ Weisong Wang, ${ }^{2}$ Eunsung Shin, ${ }^{1}$ and Guru Subramanyam (iD) ${ }^{1}$ \\ ${ }^{1}$ Center of Excellence for Thin-Film Research and Surface Engineering (CETRASE), Department of Electrical \& Computer Engineering, \\ University of Dayton, Dayton, $\mathrm{OH} 45469$, USA \\ ${ }^{2}$ Department of Electrical Engineering, Wright State University Lake Campus, Celina, OH 45822, USA
}

Correspondence should be addressed to Guru Subramanyam; gsubramanyam1@udayton.edu

Received 29 January 2018; Accepted 20 February 2018; Published 24 April 2018

Academic Editor: Gary Wysin

Copyright ( 2018 Liangyu Li et al. This is an open access article distributed under the Creative Commons Attribution License, which permits unrestricted use, distribution, and reproduction in any medium, provided the original work is properly cited.

\begin{abstract}
This paper presents tunable inductors designed with vanadium dioxide $\left(\mathrm{VO}_{2}\right)$ thin film to implement tunability. Two types of configurations, a single line coil inductor and a dual line coil inductor, are proposed. Tunable inductance is realized by thermally controlling $\mathrm{VO}_{2}$ thin film stub to be an insulator or a conductor. The measurements of inductors are taken in the frequencies range from $0.01 \mathrm{GHz}$ to $10 \mathrm{GHz}$. The electrical model has been developed to derive the corresponding inductance. The results show that the tuning range is about $69 \%$ when the temperature changes from room temperature to above the critical temperature of $68^{\circ} \mathrm{C}$.
\end{abstract}

\section{Introduction}

Tunable inductor has been a research focus for years to achieve more versatility in modern radio frequency circuits. Tunable inductors with good $Q$ values can lead to reconfigurable communication systems. Tunable inductors are building blocks of reconfiguration resonators, filters, impedance matching networks, voltage-controlled oscillators (VCOs), or power amplifiers [1]. Due to demand for high performance and small size, RF tunable inductors have a major role in RF circuit design. Although the MEMS structures were widely used in many applications, they require complex fabrication and structures $[2,3]$. To achieve high quality and low loss requirements, the size of the inductor is usually large, and the fabrication process is normally complicated compared to the device proposed in this article [4-6]. The proposed research makes it possible for a novel tunable inductive structure with smaller size and straight forward manufacturing. The structure of the tunable inductor is a planar design with simple fabrication process, and the vanadium dioxide $\left(\mathrm{VO}_{2}\right)$ thin film stubs are used as switches instead of having any movable parts such as in a MEMS switch [7, 8].

This paper highlights the latest results of a continuous effort in tunable inductor research [9]. In this study, $\mathrm{VO}_{2}$ thin films were fabricated on a sapphire substrate. The $\mathrm{VO}_{2}$ thin film is one of the insulator-to-metal (ITM) phase transition materials at a transition temperature of $68^{\circ} \mathrm{C}$ with excellent electrical properties, which is utilized as a switch in the circuit [9]. These tunable inductors are thermally controlled to accomplish variable inductance [9]. Due to a large change in electrical resistance, as well as electromagnetic properties, $\mathrm{VO}_{2}$ thin films are attractive for a wide variety of applications from RF switches to tunable antennas [9-19]. The $\mathrm{VO}_{2}$ thin films also have memristive properties, which can be demonstrated as an adaptive ("learning") filter by using a $\mathrm{VO}_{2}$ based memristor [20]. To expand applications of $\mathrm{VO}_{2}$ thin films, many methods of changing the transition temperature of $\mathrm{VO}_{2}$ have been verified. The $\mathrm{VO}_{2}$ thin films synthesized on aluminum nitride (AIN)/Si (111) substrates revealed ITM transition at $350 \mathrm{~K}\left(76.8^{\circ} \mathrm{C}\right)$ [21]. The tungsten- (W-) doped $\mathrm{VO}_{2}$ thin films revealed a decrease of the transition temperature to $321 \mathrm{~K}\left(49^{\circ} \mathrm{C}\right)$ [14]. In this study, all the inductor structures and corresponding equivalent electrical models are designed and simulated in AWR design environment. The design method of structures and fabrication are presented in Section 2. Experimental results are analyzed in Section 3. The summary and conclusions are provided in Section 4. 


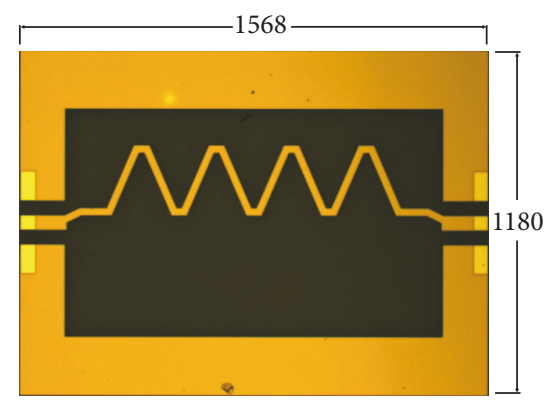

(a)

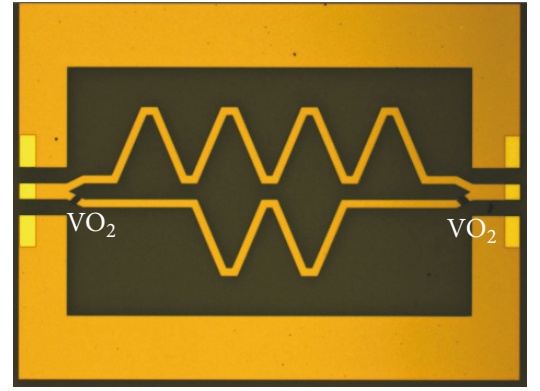

(b)

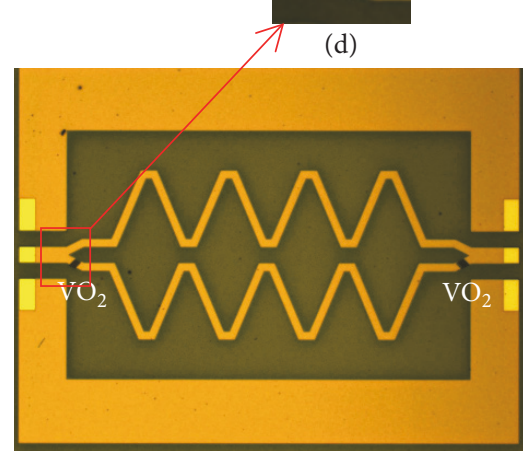

(c)

Figure 1: Top views of fabricated tunable inductors structures with (a) single line coil inductor, (b) dual line coil inductor with two turns in the bottom coil, and (c) dual line coil inductor with four turns in the bottom coil. Yellow areas are gold. Black areas on the yellow wires are the $\mathrm{VO}_{2}$ stubs. The dimension of $\mathrm{VO}_{2}$ is $23.1 \mu \mathrm{m} \times 26.3 \mu \mathrm{m}$ shown in (d). All units are in $\mu \mathrm{m}$.

\section{Tunable Inductor Designs}

The tunable inductors structures shown in Figure 1 are inductor designs studied in this paper. Figure 1(a) is the single line coil inductor without any $\mathrm{VO}_{2}$. It is used as a reference design to assess other designs with $\mathrm{VO}_{2}$. In this design, $\mathrm{Au}$ is used as the material for the inductor. Figures 1(b) and 1(c) are dual line designs with various numbers of turn parallel with the top Au only inductor. The bottom coil inductor consists of two short portions of $\mathrm{VO}_{2}$ thin film at both ends and $\mathrm{Au}$ thin film in between. Therefore, when $\mathrm{VO}_{2}$ portion is turned on by the temperature, the $\mathrm{VO}_{2}$ controlled bottom coil inductor will be turned on as well to form parallelly connected inductors. To use network analyzer to study the inductor performance, all designs use single layer coplanar structures $(1568 \mu \mathrm{m} \times 1180 \mu \mathrm{m})$ with ground/signal/ground coplanar waveguide lines. The width of the inductor coil is $25 \mu \mathrm{m}$. The $\mathrm{VO}_{2}$ thin films are deposited and patterned in the dark portion labeled in Figure 1.

At room temperature, the $\mathrm{VO}_{2}$ thin film is in the high resistivity state (insulator); the input signal of the dual line coil structures can only pass through the top metal coil but not the bottom $\mathrm{VO}_{2}$ coil, which resembles the behavior of the single line inductor. When the temperature is above $68^{\circ} \mathrm{C}$, $\mathrm{VO}_{2}$ thin film is in the low resistance state (conductive), and part of the input signal will be able to pass through the $\mathrm{VO}_{2}$ side of coil and thus the equivalent inductance of the whole structure varies.

The tunable inductor test structures were fabricated on 3 inch diameter sapphire substrate wafer. First, the $150 \mathrm{~nm} \mathrm{VO}_{2}$ thin films were deposited by pulsed laser deposition system at $500^{\circ} \mathrm{C}$ and etched in RIE. Secondly, the $350 \mathrm{~nm}$ metal layer $(20 \mathrm{~nm} \mathrm{Ti}, 30 \mathrm{~nm} \mathrm{Pt}$, and $300 \mathrm{~nm} \mathrm{Au}$ ) was deposited using electron beam evaporation technique followed by standard positive photoresist liftoff process. Lastly, a layer of photoresist is used to cover the $\mathrm{VO}_{2}$ thin film to prevent oxidation with only probing regions exposed. The details of fabrication process can also be found in our previous publication [9]. The devices were measured using an HP 8720 Vector Network Analyzer and a thermoelectric temperature controller with a frequency sweep from $0.01 \mathrm{GHz}$ to $10 \mathrm{GHz}$.

\section{Results and Discussion}

Figure 2 shows the resistivity measurement results of a $2 \mathrm{~mm}$ by $0.1 \mathrm{~mm} \mathrm{VO}_{2}$ thin film connect with two $500 \mu \mathrm{m}$ by $500 \mu \mathrm{m}$ $\mathrm{Au}$ conductor deposited on sapphire substrate. The resistivity curves show the insulator-to-metal (ITM) phase transition around $68^{\circ} \mathrm{C}$. The resistivity variation is approximately four orders of magnitude. The measured results exhibit that $\mathrm{VO}_{2}$ thin film has high quality.

The measured results of insertion loss for all inductor designs at $25^{\circ} \mathrm{C}$ are shown in Figure 3. It can be seen that all curves are almost coincident. This means that the dual line coil inductors structures behave the same as single line coil structure at room temperature. The $\mathrm{VO}_{2}$ pads act as open switches and the signal cannot be passed through the bottom inductor coil.

Measurements of scattering parameters ( $S$-parameters) for all devices at $80^{\circ} \mathrm{C}$ are given in Figure 4 . Measured insertion loss $\left(S_{21}\right)$ is in the range from $-0.7 \mathrm{~dB}$ to $-2.5 \mathrm{~dB}$ when the $\mathrm{VO}_{2}$ patches change from room temperature to 


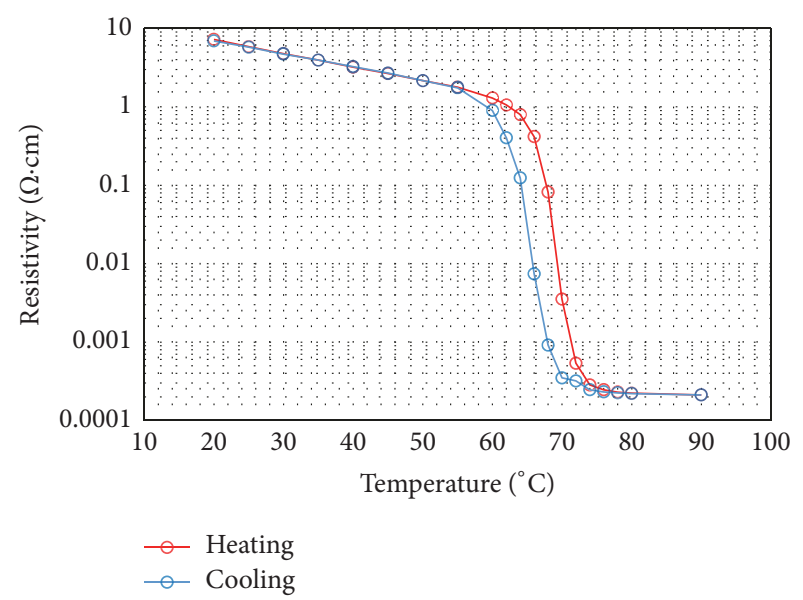

(a)

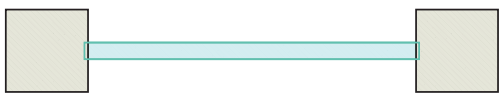

(b)

FIgURE 2: (a) Measurement results of resistivity versus temperature for a $\mathrm{VO}_{2}$ thin film on sapphire substrate (logarithm scale). (b) Top view of $\mathrm{VO}_{2}$ test structure. The dimension of $\mathrm{VO}_{2}$ bar (shown in light blue) is $2 \mathrm{~mm} \times 0.1 \mathrm{~mm}$ (length $\times$ width).

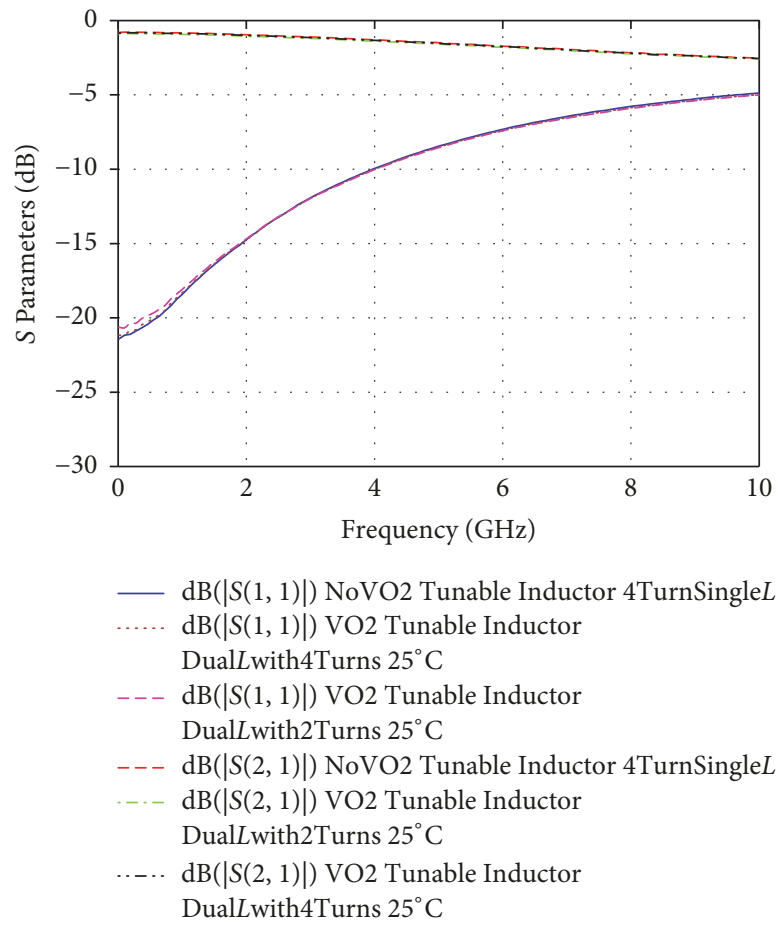

FIGURE 3: Measured results of $S_{21}$ magnitudes for single line coil inductor structure and dual line coil inductor structure at room temperature.

$80^{\circ} \mathrm{C} . S_{21}$ of dual line coil inductors is generally higher than $S_{21}$ of single line coil inductor dramatically, meaning that the $\mathrm{VO}_{2}$ thin films are in the conductive state and the signal can pass through the $\mathrm{VO}_{2}$ thin film at high temperature $\left(80^{\circ} \mathrm{C}\right)$.

The tunable inductor structures can be electrically modeled by using AWR design environment software. The equivalent electrical model for single line coil inductor (Figure 1(a)) and the equivalent electrical model for dual line coil inductors (Figures 1(b) and 1(c)) are shown in Figures 5(a) and 5(b), respectively. The effective inductance of single line coil inductor is assumed to be $L$. At room temperature, the effective inductance of dual line coil inductor is equal to the inductance of single line coil due to the signal being blocked by the insulating $\mathrm{VO}_{2}$ thin film. At high temperature, the effective inductance of dual line coil inductor can be calculated by $L$ in parallel with $L_{b}$. The value of $L_{b}$ is controlled by the various numbers of turns of the bottom coil. Inductance variation of each structure can be compared with that of the reference structure. Equivalent inductance can be extracted from this equivalent electrical model by matching the scattering parameter of the experimental results and the electrical model. Figure 6 shows the matched results. The 


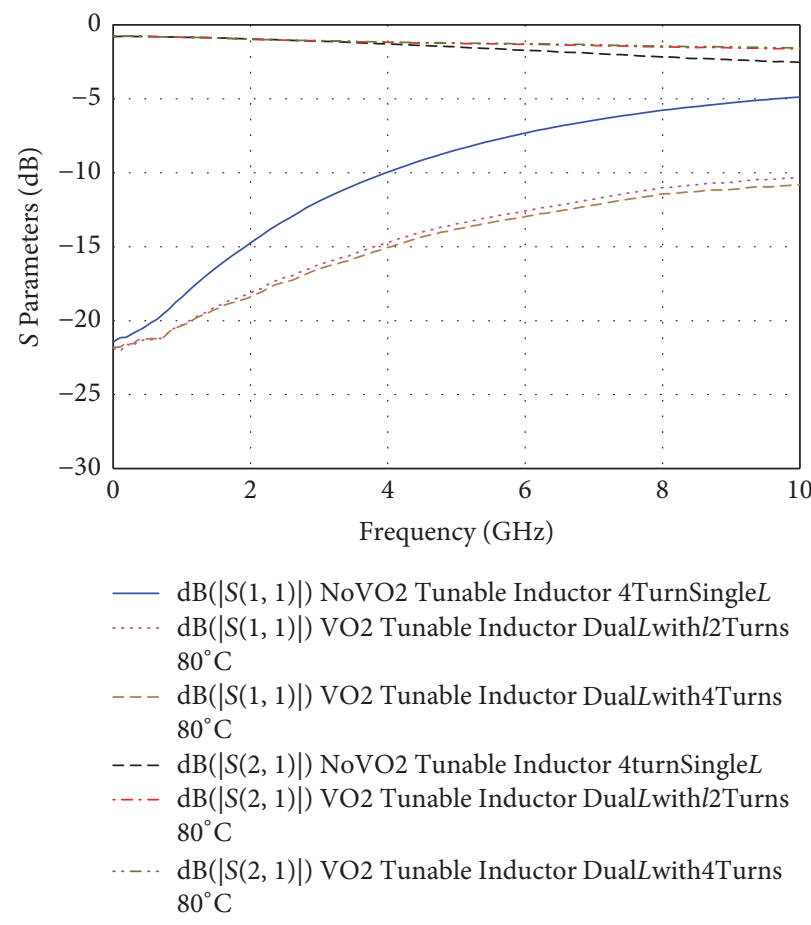

Figure 4: Measured results of $S_{21}$ magnitudes for single line coil inductor structure and dual line coil inductor structure at high temperature $\left(80^{\circ} \mathrm{C}\right)$.

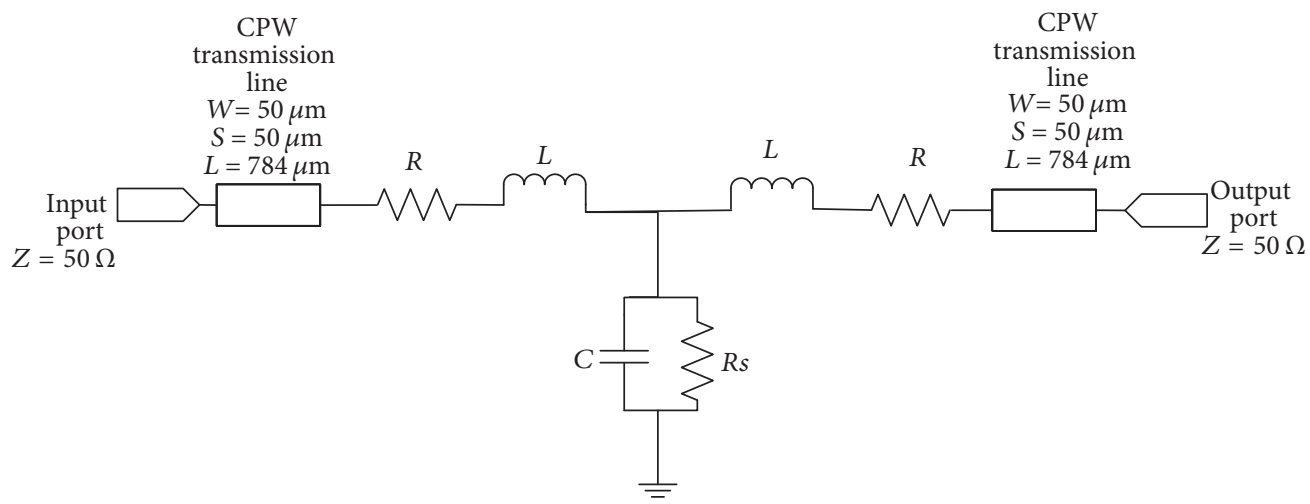

(a)

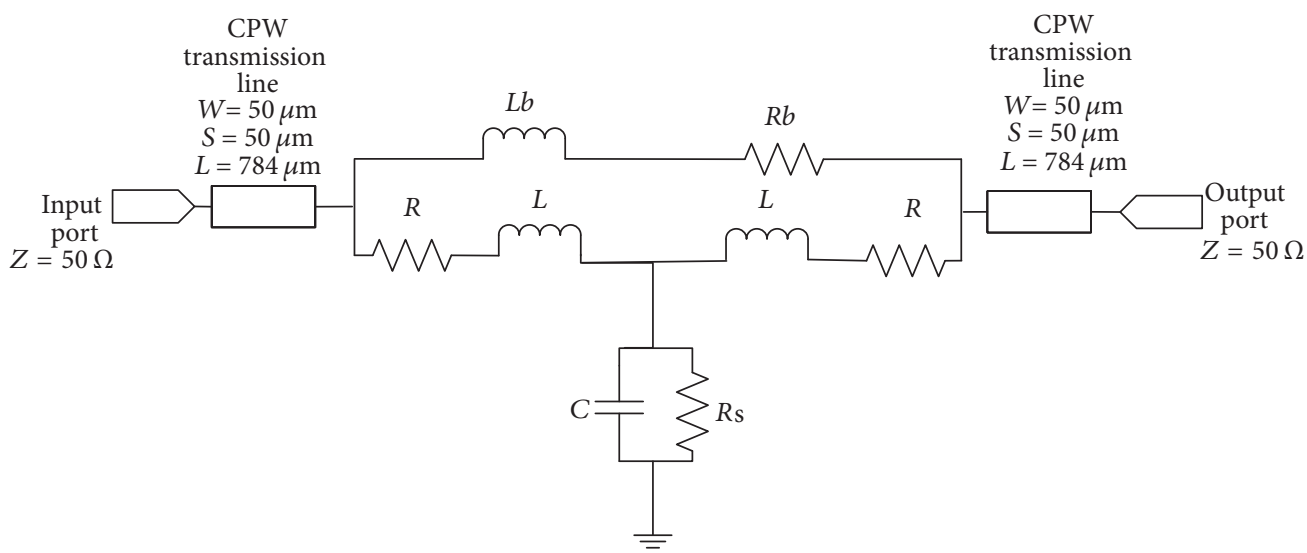

(b)

FIGURE 5: The (a) equivalent electrical model for single line coil inductor structure and (b) equivalent electrical model for dual line coil inductor structure. 


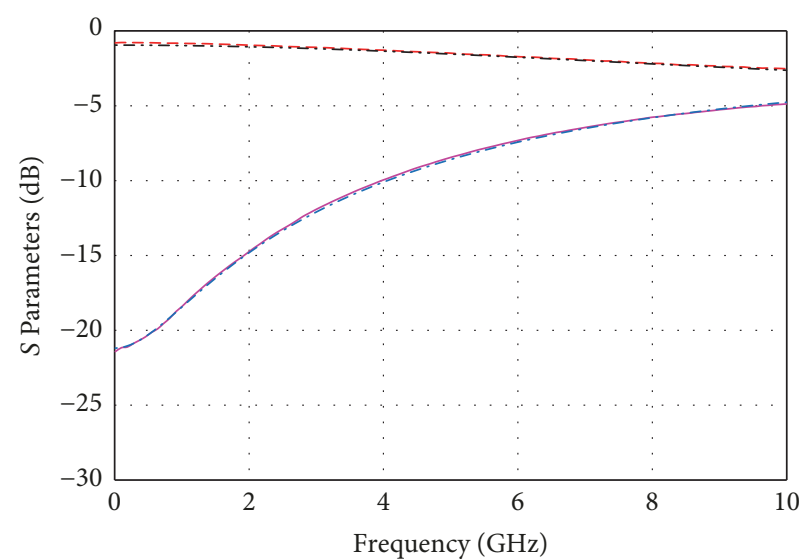

- $\mathrm{dB}(|S(1,1)|)$ NoVO2 Tunable Inductor 4TurnSingle $L$ - - $\mathrm{dB}(|S(2,1)|)$ NoVO2 Tunable Inductor 4TurnSingle $L$

.... $\mathrm{dB}(|S(1,1)|)$ Schematic Single $L$

..... $\mathrm{dB}(|S(2,1)|)$ Schematic Single $L$

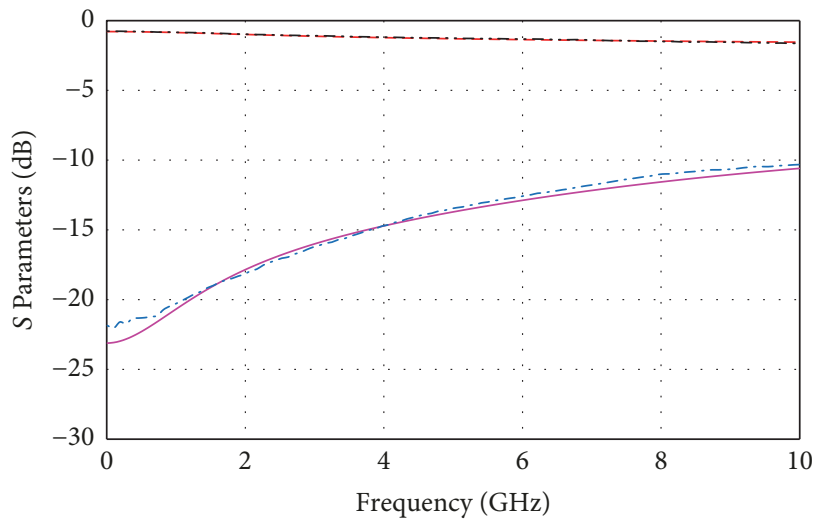

- $\mathrm{dB}(|S(1,1)|):$ Schematic 2Turns

- - $\mathrm{dB}(|S(2,1)|):$ Schematic 2Turns

...- $\mathrm{dB}(|S(1,1)|)$ : VO2 Tunable Inductor DualLwith $l 2$ Turns $80^{\circ} \mathrm{C}$

.... $\mathrm{dB}(|S(2,1)|)$ : $\mathrm{VO} 2$ Tunable Inductor DualLwith $l 2$ Turns $80^{\circ} \mathrm{C}$

(b)

(a)

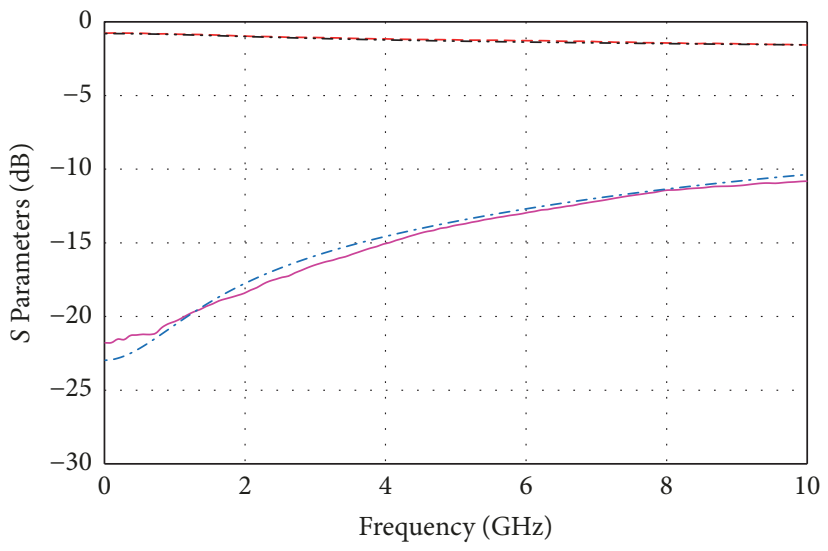

— $\mathrm{dB}(|S(1,1)|): \mathrm{VO} 2$ Tunable Inductor DualLwith4Turns $80^{\circ} \mathrm{C}$

- - $\mathrm{dB}(|S(2,1)|)$ : VO2 Tunable Inductor DualLwith4Turns $80^{\circ} \mathrm{C}$

... $\mathrm{dB}(|S(1,1)|)$ : Schematic 4Turns

..... $\mathrm{dB}(|S(2,1)|):$ Schematic 4Turns

(c)

FIGURE 6: Scattering parameter of the experimental results and the equivalent circuit model at $80^{\circ} \mathrm{C}$ for (a) single line coil inductor, (b) dual line coil inductor with two turns, and (c) dual line coil inductor with four turns.

TABLE 1: Inductance and tunability of electrical model.

\begin{tabular}{lccc}
\hline & Single line & Two turns & Four turns \\
\hline$L_{\text {total }}(\mathrm{nH})$ & 1.2 & 0.35 & 0.37 \\
Tunability & - & $70.8 \%$ & $69.2 \%$ \\
\hline
\end{tabular}

total inductance values at high temperature are matched and calculated as shown in Table 1 . The effective inductance of dual line coil inductor decreases at high temperature due to the signal can pass through the bottom coil inductor.
Tunability is defined by using [22]

$$
\text { Tunability }=\frac{L_{\text {single }}-L_{n}}{L_{\text {single }}} \times 100 \%,
$$

where $L_{\text {single }}$ is the total inductance of single line coil structure and $L_{n}$ is the total inductance of dual line coil structure, with $n$ being the number of turns in the bottom coil.

Tunability of inductors structures is summarized in Table 1 . The inductance turning is above $69 \%$ when the $\mathrm{VO}_{2}$ thin film changes from insulating at room temperature to conducting above the critical temperature of $68^{\circ} \mathrm{C}$. 


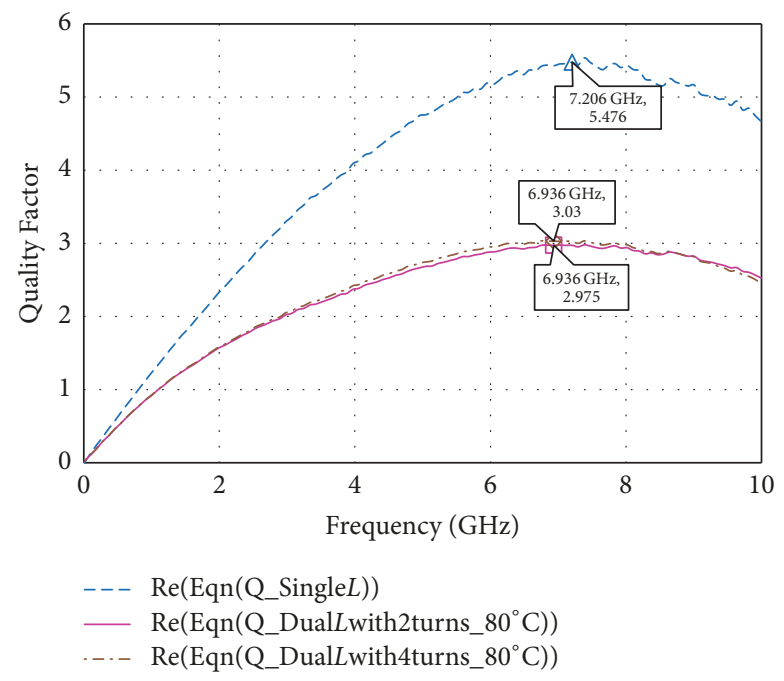

FIGURE 7: Quality factor of tunable inductors.

Quality factor ( $Q$ factor) is an important characteristic of inductors. The $Q$ factor of tunable inductor is defined as [23]

$$
Q=\left|\frac{\operatorname{Im}\left(1 / Y_{11}\right)}{\operatorname{Re}\left(1 / Y_{11}\right)}\right| .
$$

The $Y$ parameters can be converted by $S$ parameter using AWR design environment software. The $Q$ factors for tunable inductors extracted by using (2) are shown in Figure 7. The values of $Q$ factor for single line inductor and dual line inductors are less than 5.5 and 3.03, respectively. The $Q$ factor increases with increasing the number of turns.

The thin $\mathrm{VO}_{2}$ line contributes to increased series resistance which limits $Q$ for the devices. The inductor $Q$ can be improved with thicker conducting films, redesigning inductors by removing sharp edges and optimizing the inductors over specific frequencies of interest.

\section{Conclusions}

Two types of tunable inductors, single line coil inductor and dual line coil inductor, were designed, fabricated, and tested in this study. Tunable inductors using $\mathrm{VO}_{2}$ as the control material exhibited high quality in insulator phase and conductor phase. Inductance tunability and insertion loss at room temperature and above the critical temperature $\left(80^{\circ} \mathrm{C}\right)$ were compared and discussed. This demonstrated that the proposed tunable inductors have high tuning range $(>69 \%)$. Further study will be done on improving the quality factor of the inductors and integrating a heating coil with the inductor.

\section{Conflicts of Interest}

The authors declare that there are no conflicts of interest regarding the publication of this paper.

\section{Acknowledgments}

Authors acknowledge research support through the Research Collaboration Project and Air Force Office of Scientific
Research. Authors thank Mr. Tony Quach and Dr. Mike Kendra for their support of this project.

\section{References}

[1] M. Amirpour, S. Akbari, E. A. Sani, and M. N. Azarmanesh, "Varactor based tunable inductor design," in Proceedings of the 23rd Iranian Conference on Electrical Engineering, ICEE 2015, pp. 1419-1422, Iran, May 2015.

[2] G. Wang, H. Liu, H. Qiu et al., "MEMS-based fabrication of high-performance inductors with back hollow structure and ferromagnetic film," Microelectronic Engineering, vol. 168, pp. 59, 2017.

[3] S. S. Bedair, J. S. Pulskamp, C. D. Meyer, R. G. Polcawich, and I. M. Kierzewski, "Modeling, fabrication and testing of MEMS tunable inductors varied with piezoelectric actuators," Journal of Micromechanics and Microengineering, vol. 24, no. 9, Article ID 095017, 2014.

[4] Y. Yan, L. D. Geng, L. Zhang et al., "Correlation between tunability and anisotropy in magnetoelectric voltage tunable inductor (VTI)," Scientific Reports, vol. 7, no. 1, Article ID 16008, 2017.

[5] C. Koo, B. E. Leblanc, M. Kelley, H. E. Fitzgerald, G. H. Huff, and A. Han, "Manipulating liquid metal droplets in microfluidic channels with minimized skin residues toward tunable RF applications," Journal of Microelectromechanical Systems, vol. 24, no. 4, Article ID 6999969, pp. 1069-1076, 2015.

[6] D.-M. Fang, Q. Yuan, X.-H. Li, and H.-X. Zhang, "Electrostatically driven tunable radio frequency inductor," Microsystem Technologies, vol. 16, no. 12, pp. 2119-2122, 2010.

[7] R. R. Benoit, R. Q. Rudy, J. S. Pulskamp, R. G. Polcawich, and S. S. Bedair, "Advances in piezoelectric PZT-based RF MEMS components and systems," Journal of Micromechanics and Microengineering, vol. 27, no. 8, Article ID 083002, 2017.

[8] J. Givernaud, A. Crunteanu, J.-C. Orlianges et al., "Microwave power limiting devices based on the semiconductor-metal transition in vanadium-dioxide thin films," IEEE Transactions on Microwave Theory and Techniques, vol. 58, no. 9, pp. 23522361, 2010.

[9] S. Wang, W. Wang, E. Shin, T. Quach, and G. Subramanyam, "Tunable inductors using vanadium dioxide as the control 
material," Microwave and Optical Technology Letters, vol. 59, no. 5, pp. 1057-1061, 2017.

[10] C. Wu, F. Feng, and Y. Xie, "Design of vanadium oxide structures with controllable electrical properties for energy applications," Chemical Society Reviews, vol. 42, no. 12, pp. 5157-5183, 2013.

[11] I. Kim, M. Kang, and S. W. Kim, "Macroscopic thermal rectification device using vanadium dioxide thin film," International Journal of Thermophysics, vol. 38, no. 11, article no. 172, 2017.

[12] S. Lysenko, A. Rua, F. Fernandez, and H. Liu, "Optical nonlinearity and structural dynamics of $\mathrm{VO}_{2}$ films," Journal of Applied Physics, vol. 105, no. 4, Article ID 043502, 2009.

[13] G. J. Kovács, D. Bürger, I. Skorupa, H. Reuther, R. Heller, and H. Schmidt, "Effect of the substrate on the insulatormetal transition of vanadium dioxide films," Journal of Applied Physics, vol. 109, no. 6, Article ID 063708, 2011.

[14] T. Driscoll, S. Palit, M. M. Qazilbash et al., "Dynamic tuning of an infrared hybrid-metamaterial resonance using vanadium dioxide," Applied Physics Letters, vol. 93, no. 2, Article ID 024101, 2008.

[15] E. Shin, K. Pan, W. Wang et al., "Tungsten-doped vanadium dioxide thin film based tunable antenna," Materials Research Bulletin, vol. 101, pp. 287-290, 2018.

[16] K. Pan, W. Wang, E. Shin, K. Freeman, and G. Subramanyam, "Vanadium oxide thin-film variable resistor-based RF switches," IEEE Transactions on Electron Devices, vol. 62, no. 9, pp. 29592965, 2015.

[17] K. Pan, K. Freeman, D. Brown, E. Shin, W. Wang, and G. Subramanyam, "Vanadium dioxide thin film series singlepole single throw switch," in Proceedings of the IEEE National Aerospace and Electronics Conference, NAECON 2014, pp. 1-4, USA, June 2014.

[18] G. Subramanyam, E. Shin, D. Brown, and H. Yue, “Thermally controlled vanadium dioxide thin film microwave devices," in Proceedings of the 2013 IEEE 56th International Midwest Symposium on Circuits and Systems, MWSCAS 2013, pp. 73-76, USA, August 2013.

[19] L. Li, W. Wang, E. Shin, T. Quach, and G. Subramanyam, "Design of tunable shunt and series interdigital capacitors based on vanadium dioxide thin film," in Proceedings of the 2017 IEEE National Aerospace and Electronics Conference (NAECON), pp. 279-283, Dayton, OH, USA, June 2017.

[20] T. Driscoll, J. Quinn, S. Klein et al., "Memristive adaptive filters," Applied Physics Letters, vol. 97, no. 9, Article ID 093502, 2010.

[21] T. Slusar, J.-C. Cho, B.-J. Kim, S. J. Yun, and H.-T. Kim, "Epitaxial growth of higher transition-temperature $\mathrm{VO}_{2}$ films on $\mathrm{AlN} / \mathrm{Si}$," APL Materials, vol. 4, no. 2, Article ID 026101, 2016.

[22] D. Pozar, Microwave Engineering, John Wiley Sons, Fourth Edition, 2005.

[23] G. Lihui, Y. Mingbin, C. Zhen, H. Han, and Z. Yi, "High Q multilayer spiral inductor on silicon chip for $5 \sim 6 \mathrm{GHz}$," IEEE Electron Device Letters, vol. 23, no. 8, pp. 470-472, 2002. 

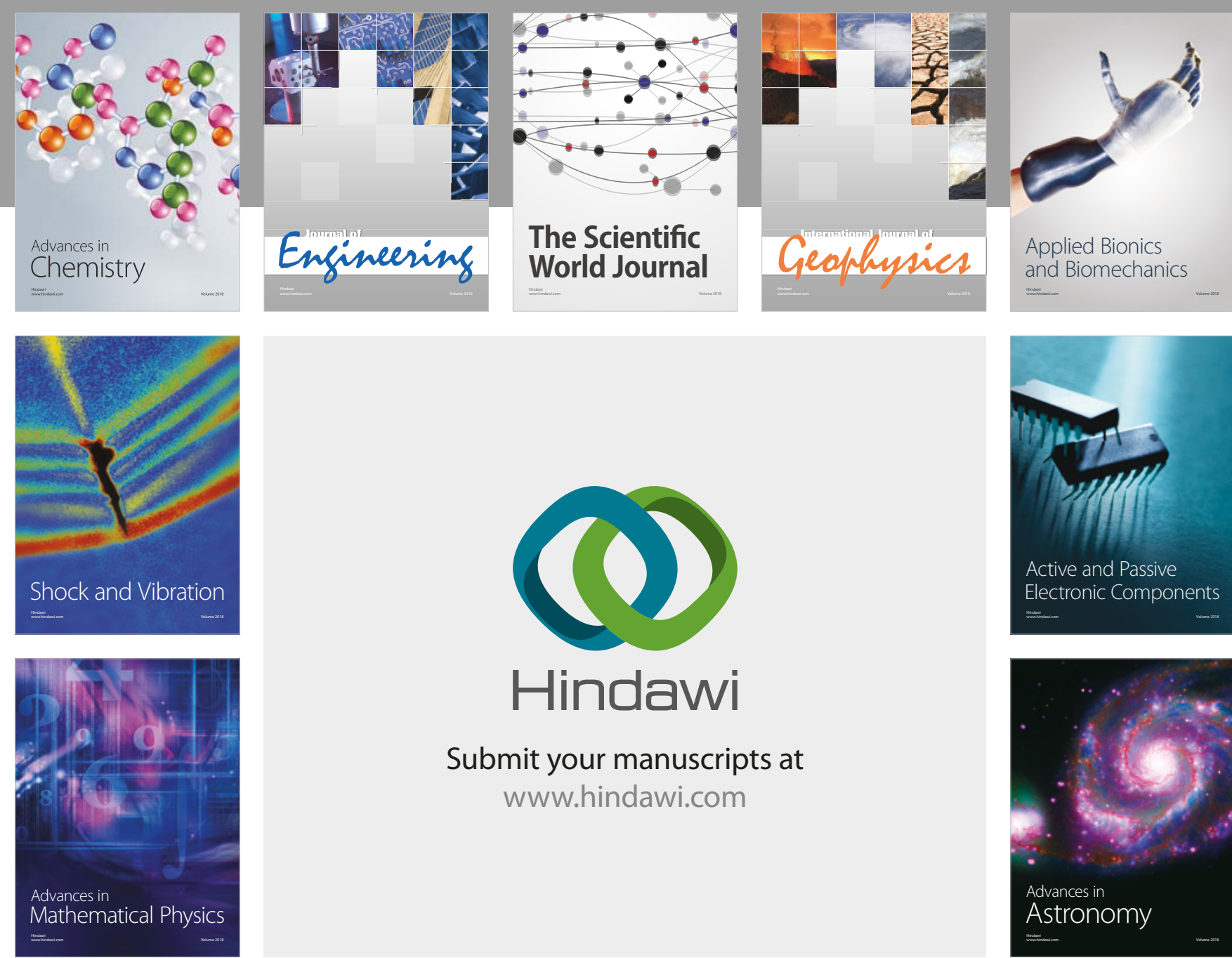

Submit your manuscripts at

www.hindawi.com

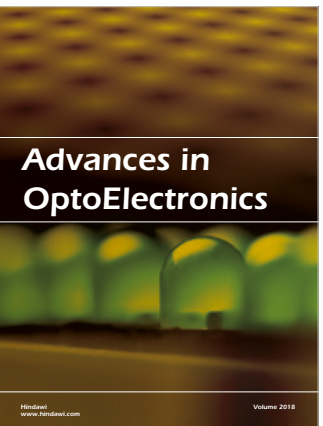

\section{Rotcting Machinery}
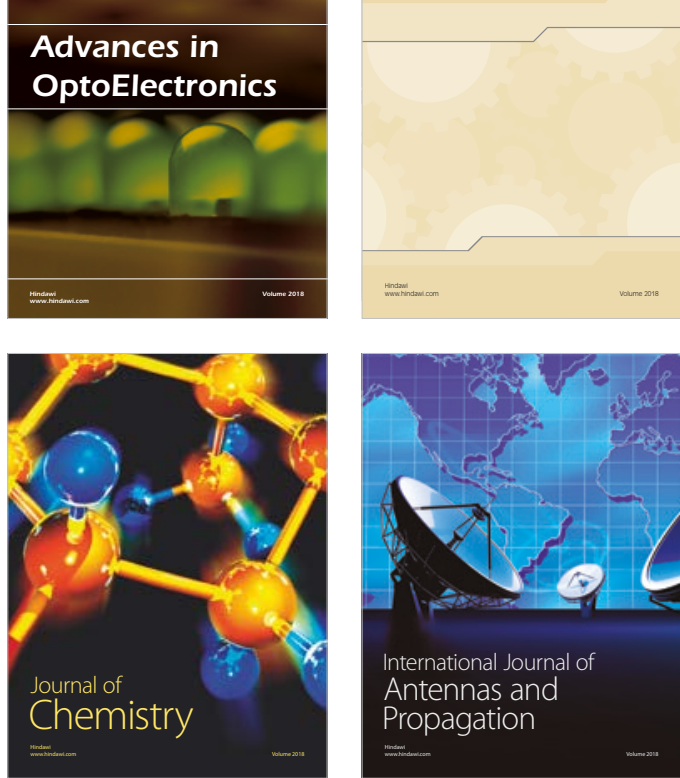

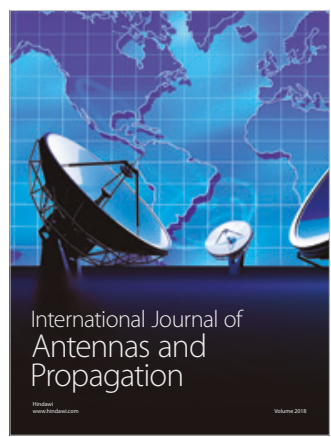

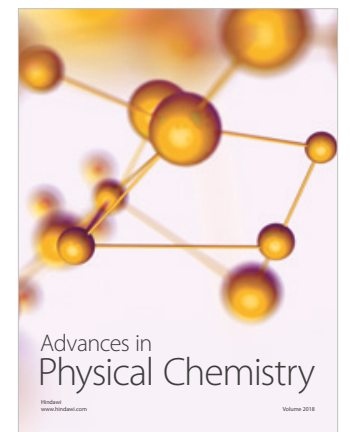

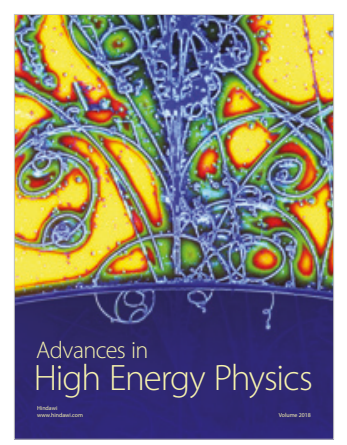

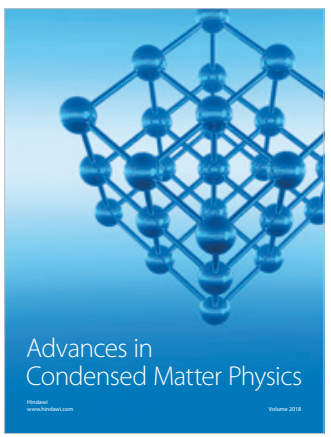

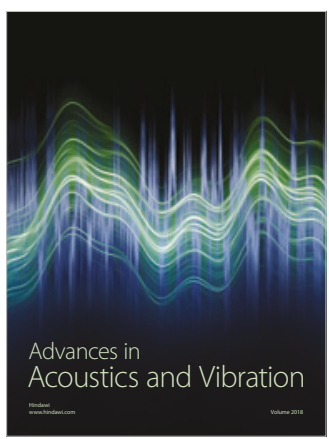

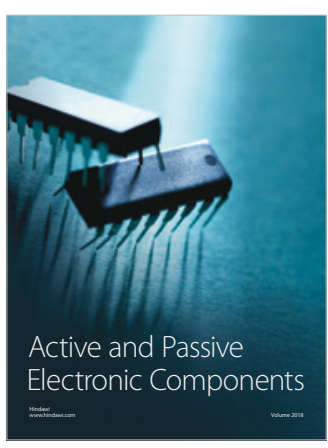
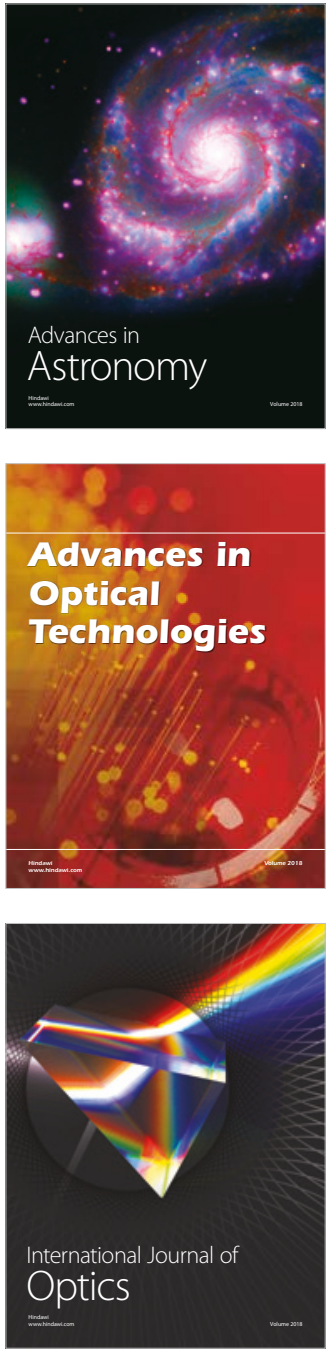